NBER WORKING PAPER SERIES

\title{
MONOPOLISTIC COMPETITION, RELATIVE \\ PRICES AND OUTPUT ADJUSTMENT \\ IN THE OPEN ECONOMY
}

Joshua Aizenman

Working Paper No. 1787

NATIONAL BUREAU OF ECONOMIC RESEARCH 1050 Massachusetts Avenue

Cambridge, MA 02138

January 1986

I would like to thank Robert Aliber, Rudiger Dornbusch, Wilfred Ethier, Jacob Frenkel, Irving Kravis, Paul Krugman, Richard Marston and Michael Mussa for helpful comments; all errors, however, are mine. Financial support by the G.S.B., University of Chicago, is gratefully acknowledged. The research reported here is part of the NBER's research program in International Studies. Any opinions expressed are those of the author and not those of the National Bureau of Economic Research. 
NBER Working Paper \#1787

January 1986

Monopolistic Competition, Relative Prices and

output Adjustment in the Open Econony

\section{$\underline{\text { ABSTRACP }}$}

The purpose of this paper is to explain price and output dynamics in an open economy characterized by a monopolistic competitive market structure in which pricing decisions incur costs. That lead producers to pre-set the price path for several periods. The paper derives an optimal pricing rule, including the optimal pre-setting horizon. It does so for a rational expectation equilibrium, characterized by staggered, unsynchronized price setting, for which the degree of staggering is endogenously determined. The discussion focuses on the critical role of the degree of domestic-foreign goods substitutability in explaining price and output effects of monetary and real shocks.

Joshua Aizenman G.S.B., University of Chicago 1101 East 58th Street Chicago, IL 60637 


\section{Introduction $^{1}$}

Empirical studies have documented a remarkable difference between the behavior of price levels and the exchange rate. ${ }^{2}$ The exchange rate between the dollar and other reading currencies follows approximately a random walk process $^{3}$, whereas changes in goods prices are autocorrelated. As a result, exchange rate innovations tend to be associated with shocks to relative prices, implying persistent deviations from purchasing power parity (PPP henceforth). 4

Debate continues, however, on the economic interpretation of these observations. Do they demonstrate that the PPP doctrine is irrelevant? Do deviations from PPP follow a random walk ${ }^{5}$ Almost any attempt to model international transmission must use some version of the law of one price, and the above empirical regularities raise question about the gap between such regularities and current modeling strategies. Random, non-persistent deviations from PPP can be readily explained in models that recognize the potential role of transportation costs and other costs of goods arbitrage. 6 Thus, it is the persistency of observed deviations from PPP that raises doubts regarding the usefulness of the PPP doctrine. There are two different interpretations for deviations from PPP: first, as deviations from the law of one price; next, as an index number problem. In other words, even if the law of one price holds for each good, the difference in consumption basket across countries implies that changes in relative prices will result in deviations from PPP. Clearly, the first interpretation causes more headaches in explaining international transmission. This paper will concentrate on this interpretation and, in order to simplify, will assume a one industry world.

The different behavior of the price levels and the exchange rate can be explained in terms of models, like that of Dornbusch (1976), that recognize 
the possibility of sluggish price adjustment in the goods market. In such an economy, the exchange rate behaves as an asset price, adjusting instantaneously to "news". The different speed of adjustment between the goods and the asset markets implies that sustained shocks to the exchange rate will result in persistent changes in relative prices.

An issue that deserves further exploration is the pricing rule used in the goods market. This rule ultimately underlies the evolution of both the real exchange rate and output. The purpose of this paper is to examine some factors determining the pricing rule, and the implications of the pricing rule for the adjustment path in response to nominal and real shocks. Specifically, I postulate a stochastic monopolistic competitive economy, where pricing decisions are carried out every several periods due to the presence of transaction costs. These costs can reflect the expenses of collecting and processing information as well as more costly consumer searches made necessary by the presence of more volatile prices. The price-setting decision periods are assumed to be distributed uniformly over time. This distribution results in price paths that differ across firms, according to the timing of their most recent pricing decision. Following the construction of the building blocks describing the economy, we drive the optimal pricing rule. Such a rule is characterized by two elements. First, for a given frequency of pricing decisions the firm needs to solve for the optimal path of prices to be pre-set at the beginning of each pricing cycle. Second, the firm needs to solve for the optimal frequency of pricing decisions.

Armed with the optimal pricing rule, I study in the next step the implications for the aggregate economy. Specifically, I investigate the adjustment of output, exchange rate and prices to nominal and real shocks and to what extent that adjustment depends on the market power enjoyed by each 
producer. The discussion focuses on the relevance of the PPP doctrine and the nature of the intermediate-run deviations from relative PPP. The doctrine of relative PPP postulates that in a world of stable relative prices, exchange rate depreciation should match inflation rate differentials. ${ }^{7}$ The paper demonstrates that, in a market characterized by monopolistic competition and costly pricing decisions, we obtain systematic deviations from relative PPP in the intermediate run, although in the long run prices adjust according to the relative PPP doctrine. The effective duration of the "intermediate run" is shown to depend on the degree of substitutability of domestic and foreign goods, and the volatility of the exchange rate. Both of these factors affect the degree of price staggering. A larger degree of substitutability between domestic and foreign goods would reduce the degree of monopoly power enjoyed by each producer and thereby reduce the pre-setting horizon. Consequently, the larger the degree of substitution, the lower is the degree of price staggering. As a result, with perfect substitution we would approach a flexible pricing equilibrium, where exact PPP would hold all the time. It is important to note, however; that quite apart from the degree of goods substitutability, relative PPP is shown to be the underlying long-run pricing rule.

The analysis also shows that unexpected monetary shocks can generate persistent aggregate output and relative price shocks, whose nature is determined by the degree of substitutability of domestic/foreign goods. There is a trade-off between price and output adjustment. A smaller substitutability between domestic and foreign goods implies that a given monetary shock induces a greater price shock but a smaller output shock. Smaller substitutability is shown to be associated with a longer pricing cycle. Thus, a greater degree of substitutability raises the magnitude but 
reduces the duration of the output shocks resulting from a given monetary innovation.

For simplicity of exposition, we focus in the paper on the pricing strategy of domestic goods, assuming that imported goods can be supplied elastically at a PPP price. This would be the case, for example, if each agent could import foreign goods, priced at their PPP level, directly. An alternative modeling strategy is to allow for a symetric treatment, in which foreign goods are sold domestically only by dealers, each of which has limited market power. In such an economy we would expect that the presence of gains from reducing the frequency of pricing decisions would generate staggered domestic prices for both domestic and foreign goods. The properties of such an equilibrium are studied in Appendix B, which shows that, apart from the added complexity, the deviations from PPP generated in such an economy are similar to those analyzed in the paper itself. Appendix B also demonstrates that the pricing cycle tends to be longer for home goods relative to the duration of the pricing cycle of foreign goods. This finding is consistent with empirical findings (see, for example, Katseli (1984)).

A growing body of current research has recognized the importance of a limited degree of goods substitutability in explaining transmission of macro shocks. Svennson (1985) takes this line of research in a closed economy context, while Dornbusch (1985) and Giovannini (1985) address it in an open economy framework. These authors study adjustment to macro shocks in a monopolistic competitive economy, where some prices are pre-set one period before the realization of shocks. A novel aspect of the present paper is in assessing those questions in an economy characterized by a staggered, unsynchronized price setting. An important element in the present analysis will be the endogenous derivation of the degree of staggering, and the 
emphasis on the role of the market power of sellers in determining the persistency of deviations from PPP, and the induced output shocks.

Section 2 of the paper describes the model. It starts with a formulation of the producer problem in a flexible price equilibrium. This equilibrium is used as a benchmark for the equilibrium obtained in the presence of costs of pricing decisions. The section ends by determining the rational expectation equilibrium for the case of a stable covariance structure where pricing decisions are made in an unsynchronized manner. Section 3 studies the stochastic properties of prices and deviations from PPP. Section 4 adds the money market equilibrium, analyzing the output effects of monetary shocks. Section 5 evaluates the adjustment of prices and output to real shocks. Section 6 provides concluding remarks. Appendix A and B derive the optimal pricing formulas and the pre-setting horizon. 


\section{The Model}

Let there be $\ell$ domestic producers, organized in a monopolistic-

competitive manner. ${ }^{8}$ All of them face the same demand curve and share the same technology. Demand facing producer $k$ is given by

$$
D_{k}=\left[\prod_{\substack{j=1 \\ j \neq k}}^{\ell} \frac{P_{j}}{P_{k}}{ }^{B}\right]\left(\frac{E P^{*}}{P_{k}}\right)^{\alpha}
$$

where $E$ is the exchange rate, $P^{*}$ is the foreign price of importables, and $\mathrm{P}_{j}$ is the price charged by producer $j$. The demand facing producer $k$ reflects two sources of potential competition: all the other domestic producers (as reflected in the first term); and foreign goods, priced domestically as $\mathrm{EP}^{*}$ (as reflected in the second term). 9 An alternative presentation of the demand facing producer $k$ is:

$$
\left.D_{k}=\prod_{\substack{j=1 \\ j \neq k}}^{\ell}\left(P_{j}\right)^{\beta}\right]\left(E P^{*}\right)^{\alpha} \quad P_{k}^{-\delta} \text {, where } \delta=\beta(\ell-1)+\alpha, \delta
$$

being the own price-demand elasticity. We assume that $\delta>1$.

$$
\text { Production technology is given by }
$$

$$
q\left(L_{k}\right)^{\gamma} \quad r<1
$$

where $L_{k}$ corresponds to the labor input used by producer $k$. The domestic price deflator is denoted by $\overline{\mathrm{P}}$, where

$$
\bar{P}=\left[\prod_{j=1}^{\ell} P_{j}\right]^{1 / \ell}
$$


In order to abstract from considerations concerning the labor market we assume that the real wage in terms of the domestic product is given. To simplify presentation, we neglect both the potential role of traded input in the production process, and the possibility that labor is paid according to a CPI index, reflecting the share of foreign goods. The country is taken to be small enough to face a given foreign price, assumed to be unity $\left(P^{*}=1\right)$. The only source of uncertainty is the exchange rate (in Sections 4-5 we will study the adjustment to monetary and productivity shocks).

Consider a hypothetical flexible equilibrium, under which a producer $k$ sets his price $\left(P_{k}\right)$ at the level that would maximize profits. The flexible equilibrium price is denoted by $\tilde{\mathrm{P}}_{k}$. This equilibrium will be used as a benchmark for subsequent discussion. Producer $k$ is assumed to take the price of his competitors as given. To simplify notation, lower-case letters denote the logarithmic value of the corresponding upper-case variable (i.e., $x$ $=\log X)$. Maximization of profits reveals that:

$$
\tilde{p}_{k}=\bar{\theta}_{0}+\bar{a} e+\bar{b} \sum_{\substack{j=1 \\ j \neq k}}^{\ell} p_{j}
$$

where $\bar{\theta}_{0}=\log \left(\frac{\bar{\gamma} \delta-\frac{1}{\ell}}{\delta-1} q^{-\bar{\gamma}}\right) /\left[\delta(\bar{\gamma}-1)+1-\frac{1}{\ell}\right] ; \bar{a}=\frac{a(\bar{\gamma}-1)}{\delta(\bar{\gamma}-1)+1-\frac{1}{\ell}}$;

$$
\bar{b}=\frac{\frac{1}{\ell}+B(\bar{\gamma}-1)}{\delta(\bar{\gamma}-1)+1-\frac{1}{\ell}} ; \text { where } \bar{\gamma}=\frac{1}{\gamma}:
$$


Several observations are in order. First, $\bar{a}$ and $\bar{b}$ are linked together by an additive property:

$$
\bar{a}+(\ell-1) \bar{b}=1 \text {. }
$$

Thus, in a flexible price equilibrium $\tilde{p}_{k}$ diverges from $\bar{\theta}_{0}$ by a weighted average that corresponds to the exchange rate (weighted by $\bar{a}$ ) and to domestic producer prices (each weighted by $\bar{b}$ ). This additive property corresponds to the homogeneity postulate: an equi-proportional rise in all competitors' prices raises $p_{k}$ at the same rate. The parameter a corresponds to the elasticity of demand with respect to the price of foreign goods. Notice that as a approaches infinity, $\bar{a}$ approaches unity, while $\bar{b}$ and $\bar{\theta}_{0}$ approaches zero. Thus, at the limit of perfect substitutability we find an exact version of PPP: that is, a given change in the (domestic currency price) of foreign goods results in an equal change in the price of domestic goods (in a flexible-price equilibrium).

If all domestic prices are flexible, our assumptions regarding domestic producers imply that all producers will charge the same price, $\tilde{p}$. From (4) we obtain that in such a case:

$$
\tilde{p}-e=\frac{\bar{\theta}}{\bar{a}} \text {. }
$$

Equation 6 defines the relative price that is observed in a flexible equilibrium. This price will be shown to define the long run relative PPP price. Notice that the extent to which the flexible equilibrium deviates from the law ot one price corresponds to the absolute value of $\bar{\theta}_{0} / \bar{a}$. As the substitutability between domestic and foreign goods increases, we approach the law of one price (as $\alpha \rightarrow \infty, \bar{\theta}_{0} / \bar{a} \rightarrow 0$ ). 
We proceed by assuming the presence of gains from pre-setting the price path for several periods. Those gains represent savings in the costs of frequent collection and processing of new information as well as the cost of changing prices. ${ }^{10}$ A related discussion, though in a different context, can be found in Mussa (1981); Rotemberg (1982) and Sheshinski and Weiss (1977). These authors consider the role of the cost of changing posted prices, whereas the present analysis focuses on the role of fixed costs related to each pricing decision. As a result, their analysis resulted in a policy of presetting a price for the relevant pricing horizon, whereas the present paper sets a price path for the pricing cycle. This difference is relevant for the rational expectation solution in a staggered pricing equilibrium. 11

For simplicity of exposition, we focus in the paper on the pricing strategy of domestic goods, assuming that imported goods can be supplied elastically at a PPP price $\left(P^{*} E\right)$. This would be the case, for example, if each agent could import foreign goods, priced at their PPP level, directly. An alternative modeling strategy is to allow foreign goods to be sold domestically only by domestic dealers, each of which has limited market power. The properties of such an equilibrium are studied in Appendix B, which shows that, apart from the added complexity, the deviations from PPP generated in such an economy are similar to those analyzed in the paper.

Suppose that, due to the presence of gains from pre-setting the price path, producers make a pricing decision each $n$ periods (The economic determination of $\mathrm{n}$ is studied in Appendix A). At the beginning of each pricing cycle, a producer sets the price path for the next $n$ periods. The price in period $d$ that was pre-set $h$ periods ago is denoted by $P_{d}^{h} \cdot$ For example, a producer who starts a pricing cycle in period $t$ should decide the path of $\left(p_{t}^{0}, p_{t+1}^{1}, \ldots p_{t+n-1}^{n-1}\right)$. Figure 1 describes the price prevailing 


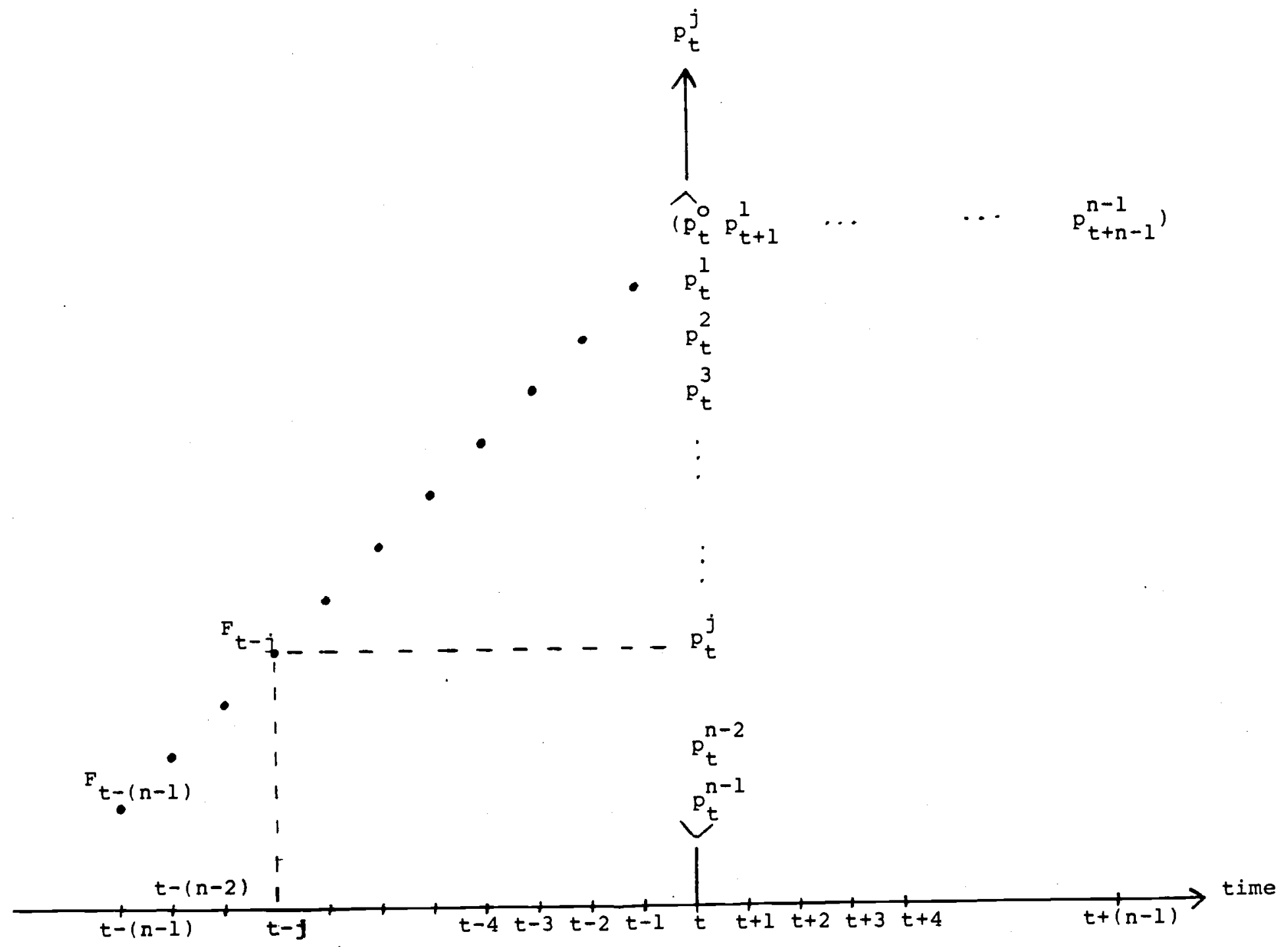

Figure - 1 
in our economy. At time $t$ n prices are observed, as described by the vertical vector of $p_{t}^{j}(0 \leq j \leq n-1)$. The points $F_{t-j}$ specify the timing of the pre-setting of the price $p_{t}^{J}$ as indicated on the horizontal axis ( $t-$ $j)$. A producer charging $p_{t}^{o}$ in period $t$ is pre-setting prices at period $t$ for the next $n$ periods, as described by the horizontal vector $\left(p_{t+j}^{j}\right), 0 \leq j \leq n-1$. In doing so he uses his information regarding all the prices that have already been set, the expected path of the exchange rate (corresponding to the domestic price of foreign goods) and the prices that other competitors are expected to set in the future. Appendix A shows that the optimal pricing rule is:

$$
p_{t+j}^{j}=E_{t}\left(\tilde{p}_{t+j}\right) ; 0 \leq j \leq n-1
$$

where $E_{t}$ is the expectation operator, conditional on the information available in period $t$. Equation (7) corresponds to a rule that pre-sets prices at the expected flexible equilibrium path.

We assume a stable stochastic structure, and unsynchronized price setting. Thus, at period $t$ we can find $n$ types of domestic producers, differentiated only by the timing of their price pre-setting decision. Assuming a large number of identical domestic producers, whose price setting decision periods are uniformly distributed over time, implies that at each period there are $m$ producer's who set the price path for the next $n$ periods, where $\ell / n=m$.

Consider a producer that pre-sets prices today for the next $n$ periods. From (4) and (7) we find that

$$
p_{t}^{0}=\bar{\theta}_{0}+\bar{a} e_{t}+\bar{b} m \sum_{j=1}^{n-1} p_{t}^{j}+\bar{b}(m-1) p_{t}^{0} .
$$


Such a producer is faced with m producers that pre-set prices $j$ periods ago (hence their present price is $p_{t}^{j}$ ), $1 \leq j \leq n-1$, and $m-1$ producers of his type. Thus, ( 8 ) can be rewritten as:

$$
\begin{gathered}
p_{t}^{o}=\theta_{0}+a e_{t}+b \sum_{j=1}^{n-1} p_{t}^{j} \\
\text { where } \theta_{0}=\frac{\bar{\theta}_{0}}{1-\bar{b}(m-1)} ; a=\frac{\bar{a}}{1-\bar{b}(m-1)} ; b=\frac{\bar{b} m}{1-\bar{b}(m-1)}
\end{gathered}
$$

Notice that $a+(n-1) b=1$. For large $\ell$ we find from the definitions that $a \simeq \frac{\bar{a}}{1-(1-\bar{a}) / n}, b \simeq \frac{1-\bar{a}}{n-(1-\bar{a})}$. Note that the values of the parameters "a" and "b" drop with the degree of staggering (n). "a" rises and "b" drops with the degree of substitutability between domestic and foreign goods $(\alpha)$.

We proceed by imposing the following structure: the exchange rate follows a random walk process with a trend:

$$
e_{t}=e_{t-1}+\varepsilon_{t}+\mu, \varepsilon_{t} \sim N\left(0, \sigma_{\varepsilon}^{2}\right)
$$

To simplify, the exchange rate path is taken at this stage to be exogenously given. Section 4 determines the exchange rate endogenously, by adding the money market. ${ }^{12}$ Each producer is assumed to know all present prices, and the structure of the economy. From equation (7) it follows that if a producer pre-sets prices for period $t \quad j$ periods ago, he did so at the expected flexible equilibrium level. But the flexible equilibrium price at 
$t$ is $p_{t}^{o}$, thus:

$$
p_{t}^{j}=E_{t-j} p_{t}^{o}
$$

Invoking the assumption of rational expectations, we can solve the system defined by (9)-(11) recursively. By applying the expectation operator $E_{t-(n-1)}$ to (9) we find, (using (11)) that:

$$
p_{t}^{n-1}=\theta_{0}+a E_{t-(n-1)} e_{t}+b(n-1) p_{t}^{n-1}
$$

Thus:

$\left(12^{\prime}\right)$

$$
p_{t}^{n-1}=\frac{\theta_{0}}{a}+E_{t-(n-1)} e_{t} \text {. }
$$

Alternatively:

$\left(12^{\prime \prime}\right)$

$$
p_{t}^{n-1}-E_{t-(n-1)} e_{t}=\frac{\bar{\theta}_{0}}{\bar{a}}
$$

Next, applying $E_{t-(n-1)}$ to (9), using (12'), we obtain:

$$
\begin{gathered}
p_{t}^{n-2}=\theta_{0}+a E_{t-(n-2)} e_{t}+b\left[E_{t-(n-1)} e_{t}+\frac{\theta_{0}}{a}\right]+b(n-2) p_{t}^{n-2} \\
\text { Applying (10) to }(13):
\end{gathered}
$$

$$
p_{t}^{n-2}=\frac{\theta_{0}}{a}+E_{t-(n-1)} e_{t}+\frac{a}{1-b(n-2)} \varepsilon_{t-(n-2)}
$$

alternatively:

$$
p_{t}^{n-2}-E_{t-(n-2)} e_{t}=\frac{\bar{\theta}_{0}}{\bar{a}}-\frac{b}{a+b} \varepsilon_{t-(n-2)}
$$

Following this process recursively, we find that (for $n-2 \geq j \geq 0$ ):

$$
p_{t}^{j}=\frac{\theta_{0}}{a}+E_{t-(n-1)} e_{t}+\sum_{k=j}^{n-2} \frac{a}{a+(n-1-k) b} \varepsilon_{t-k}
$$


The resultant pre-setting rule is now specified by (12') and (14).

Several observations are in order. A relative PPP pricing rule implies equality between domestic price changes and the expected changes in the exchange rate. This holds precisely for the pre-setting of prices $n-1$ periods ahead, $\left(12^{\prime}\right)$, where the price is set such as to equate the expected relative price ( $p-e)$ to the "non-stochastic" equilibrium ${ }^{13}, \frac{\theta_{0}}{a}$. This implies that $p_{t}^{n-1}$ is allowed to adjust fully to expected depreciation. 14 This pricing rule reflects the fact that a producer who pre-sets the price for period $t$ in period $t-(n-1)$ (at level $p_{t}^{n-1}$ ) is taking into account the expected price of his competitors. His best estimate for the price that his domestic competitors would charge at period t equals his own price. ${ }^{15}$ This observation stems from the fact that the price of his domestic competitors would deviate from his own price $\left(p_{t}^{n-1}\right)$ only by the innovations $\varepsilon_{t-j}(n-2 \geqslant j \geqslant 0)$ that are orthogonal to his present information set. Consequently, a producer who pre sets prices for period $t$ at period $t-(n-1)$ would treat his domestic competitors symmetrically. This implies that the pricing rule would follow the expected relative PPP version of equation (6), as is shown by equation $12 \%$. For a pre-setting horizon shorter than $n-1$, we obtain a pricing rule under which deviations from relative PPP reflect the interaction between the market structure and inovations in the exchange rate. For example, a producer who pre-sets the price for period $t$ at period $t-(n-2)$ knows that some other producers have already set their price in period $t-(n-1)$ for $t$ at the level $p_{t}^{n-1}$. The producer has an informational advantage relative to those that have already set their prices, because he knows the innovation in the exchange rate $\varepsilon_{t-(n-2)}$. Using the logic of footnote 15 , he expects that the producers who have not yet pre-set their price for period $t$ to set it at the level that he sets. There are two 
forces at work: on the one hand a larger substitutability with foreign goods (larger $a$ ) encourages him to adjust his prices (relative to $p_{t}^{n-1}$ ) by the innovation, $\varepsilon_{t-(n-2)}$. On the other hand, a larger substitutability with other domestic producers ( $\beta$ ) discourages him from doing so because, by adjusting his price by the innovation, he is likely to lose costumers to producers who have preset their prices at period $t-(n-1)$ (assuming $\left.\varepsilon_{t-(n-2)}>0\right)$. As is revealed by equation 13", the producer will adjust his price by a portion $a /(a+b)$ of the innovation, reflecting the relative strength of these two forces. The expected relative PPP pricing rule would set $p_{t}^{n-2}$ at $\frac{\theta_{0}}{a}+E_{t-(n-2)} e_{t}$. Thus, actual $p_{t}^{n-2}$ deviates from a relative PPP rule by $\varepsilon_{t-(n-2)} \frac{b}{a+b}$. Note that as we approach a perfect substitutability between domestic and foreign goods (that is as $a \rightarrow \infty$ ), $a \rightarrow 1$ and $b+0$. In such a case, $\frac{b}{a+b}$ approaches zero, and one gets an exact expected PPP pricing rule. This result holds for all horizons, because $\frac{a}{1-k b} \rightarrow 1$ as $a+\infty$ (for $k \leq n$ ). In general, a smaller substitutability with foreign goods and a shorter pre-setting horizon (i.e., smaller $j$ in equation 14) will magnify deviations from the expected PPP pricing rule. For example, a producer that set $p_{t}^{j}(j<n-1)$, will adjust its price relative to the last pre-set price $\left(p_{t}^{j+1}\right)$ by a portion $\frac{a}{a+(n-1-j) b}$ of the exchange rate shock that occurred between period $t-j$ and $t-(j+1)$. Note that the shorter the presetting horizon ( $\operatorname{smaller} j$ in $\mathrm{p}_{t}^{j}$ ), the smaller the price elasticity with respect to the exchange rate. This result reflects the fact that a shorter pre-setting horizon (smaller $\mathrm{j}$ ) means that more producers had already set their price for period $\mathrm{n}$. Thus, there is a greater potential loss associated with an attempt to adjust $p_{t}^{j}$ according to $\varepsilon_{t-j}$.

Next, we turn to the derivation of the domestic price deflator in our economy, which corresponds to a simple average of the $p_{t}^{j}$ : 


$$
\bar{p}_{t}=\frac{1}{n} \sum_{j=0}^{n-1} p_{t}^{j}
$$

where $\bar{p}$ refers to the price level. Note that applying (15) to (9) we find that:

$$
p_{t}^{o}=\theta_{0}+a e_{t}+b\left(n \bar{p}_{t}-p_{t}^{o}\right)
$$

Combining (14) (for $j=0$ ) and (16) we solve for the price level:

$$
\bar{p}_{t}=\frac{\theta_{0}}{a}+E_{t-(n-1)} e_{t}+\frac{a}{n} \sum_{j=0}^{n-2} \frac{j+1}{1-j b} \varepsilon_{t-j}
$$

From (17) we find that relative prices, or in our case deviations from the law of one price, are:

$$
e_{t}-\bar{p}_{t}=-\frac{\theta_{0}}{a}+\sum_{j=0}^{n-2}\left(1-\frac{a}{n} \frac{1+j}{1-j b}\right) \varepsilon_{t-j}
$$

Or, alternatively:

$$
e_{t}-\bar{p}_{t}=-\frac{\theta_{0}}{a}+\sum_{j=0}^{n-2} \frac{n-a}{n}\left(\frac{n-1-j}{n-1-j+j a}\right) \varepsilon_{t-j} .
$$

\section{The Stochastic Properties of Deviations from PPP}

The previous section has derived the reduced form for average prices and deviations from PPP. From (17) we see that a current exchange-rate shock $\left(\varepsilon_{t}\right)$ would affect present average prices by $\frac{a}{n}$. It would also affect future average prices, $j$ periods ahead, by $\frac{a}{n} \frac{j+1}{1-j \cdot b}(0 \leq j \leq n-2)$. Thus, its net effect on prices would increase over time, at an accelerated rate. After $n$ periods, it would achieve its full effect on the price level. The opposite path applies for the effect of an exchange rate shock $(\varepsilon)$ on relative prices $(e-\bar{p})$. It would at once affect relative prices by $\left(1-\frac{a}{n}\right)$. Its impact would diminish over time at an accelerated rate. Figures $2 a-2 b$ plot the effect of an exchange-rate shock $\left(\varepsilon_{0}=1\right)$ on relative prices 

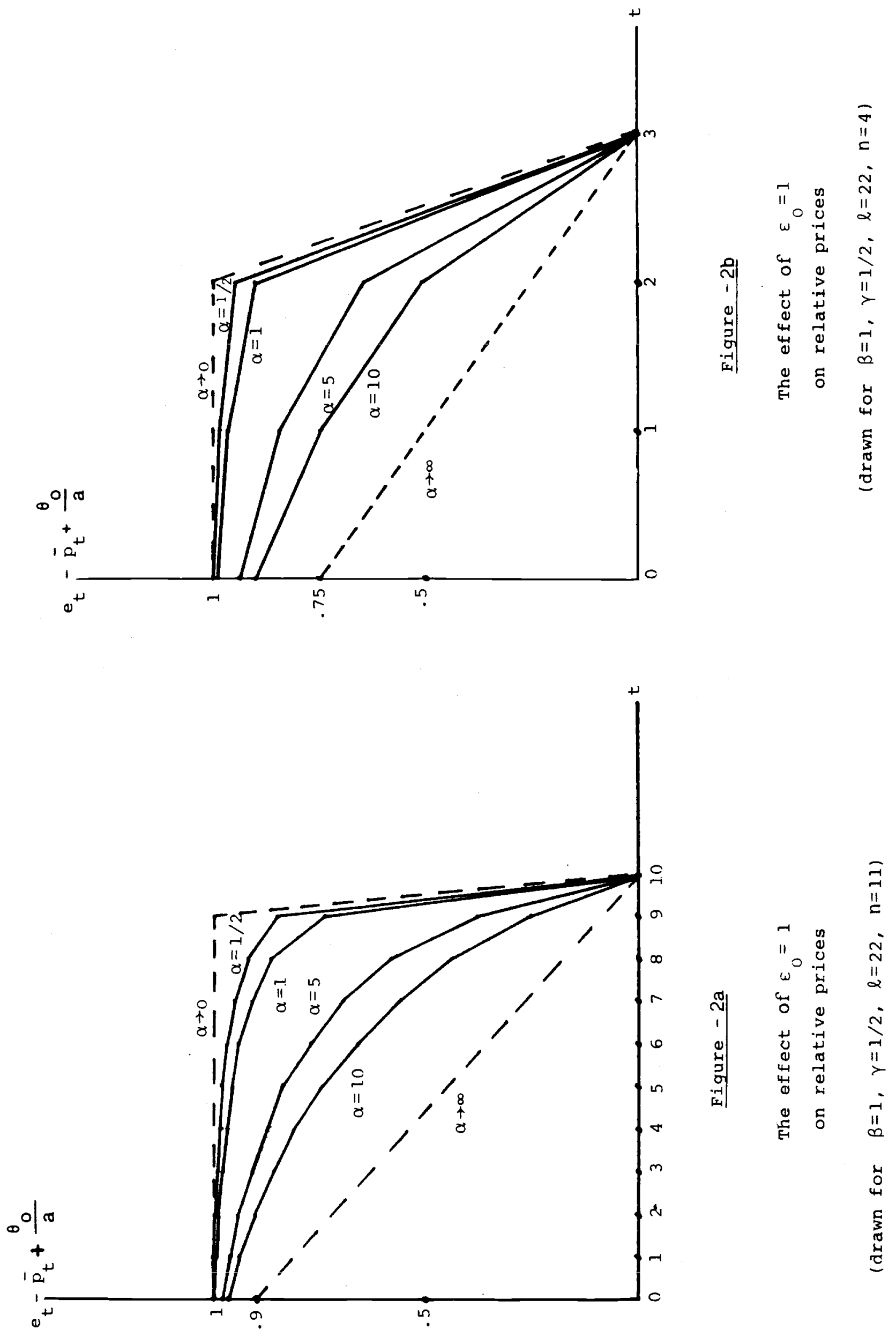
for the case in which $\gamma=1 / 2, \beta=1, \ell=22, n=11$ and 4 . It allows for different elasticities of substitution between domestic and foreign goods $(\alpha=0,1 / 2,1,5,10, \infty)$. Note that in the first part of the cycle the exchange-rate shock represents a relative price shock, and there is high degree of persistency in the resultant path of relative prices. At some stage, however, we enter a second stage of the cycle, in which the shock to relative prices dies down at an accelerated speed. A lower substitutability between domestic and foreign goods $(d \alpha<0)$ prolongs the first part of the cycle, making the second part shorter. Consequently, the decay of the relative price shock that takes place in the second period is more abrupt. 16 This dependence of the path of relative prices on a can be shown to be independent of the specific parameter values in this example. A possible persistency measure is the duration of the time (relative to the cycle length, $n-1$ ) needed to eliminate half of the effect of an exchange-rate shock on relative prices. From (19) we find that it will take $j^{*}=\frac{n-2 a}{1+a+b}$ periods to eliminate half of the effect of an exchange rate shock on relative prices. It can be shown that for large $n$

$$
\left[j^{*}-\left(\frac{n-1}{2}\right)\right] /\left(\frac{n-1}{2}\right) \simeq \frac{1-\bar{a}}{1+\bar{a}} .
$$

Thus, $j^{*}$ exceeds half of the pricing cycle $\left(\sim\left(\frac{n-1}{2}\right)\right)$ by $\frac{1-\bar{a}}{1+\bar{a}}$. A smaller value of the substitutability between domestic and foreign goods (smaller $\bar{a}$ ) magnifies the effect of a given exchange rate shock on relative price by "prolonging" its effective influence on deviations from PPP.

We can now apply (17)-(18) to obtain a solution for the covariation of exchange rates and prices. It can be shown that

$$
\operatorname{cov}\left(\bar{p}_{t}-\bar{p}_{t-1} ; e_{t}-e_{t-1}\right)=\mu^{2}+\frac{a}{n} \sigma_{\varepsilon}^{2}
$$




$$
\operatorname{cov}\left(e_{t}-\bar{p}_{t}-\left(e_{t-1}-\bar{p}_{t-1}\right) ; e_{t}-e_{t-1}\right)=\left(1-\frac{a}{n}\right) \sigma_{\varepsilon}^{2}
$$

The covariation of prices and exchange rate depends on the sum of two components: the first reflects the trend, the second the volatility of the exchange rate weighted by the elasticity of the contemporaneous price with respect to the exchange rate, $\frac{a}{n}$. Thus, for inflationary countries the first term will tend to dominate. For such countries, $\mu$ will be tightly related to monetary expansion, and we would expect monetary growth to be tightly correlated with changes in the exchange rate and prices. For countries with low and similar inflationary trends, the first term in equation (21) will tend to be of lesser importance, and the covariation will depend on $\frac{a}{n}$. For a low degree of substitutability of domestic and foreign goods, and a longer pricing cycle (a larger $n$ ), $\frac{a}{n}$ will tend to be small, implying a small covariation of prices and exchange rates.

Appendix A derives the optimal pre-setting horizon, $\mathrm{n}$ (equal also to the extent of contract staggering), which is shown to decrease with $a^{2} \sigma_{\varepsilon}^{2}$. A larger degree of substitutability between domestic and foreign goods (da>0 which implies da>o), as well as a more volatile exchange rate will reduce the pre-setting horizon. At the limit of perfect substitutability $(\alpha \rightarrow \infty) n$ is shown to approach one, and relative PPP holds at all time. Thus, a necessary condition for generating deviations from relative PPP is a limited degree of substitutability between domestic and foreign goods. A lower substitutability $(d \alpha<0)$ will raise $n$ and reduce a, implying that relative prices $e_{t}-\bar{p}_{t}$ will behave as a moving average of a higher order. For a large $n$ we might find that relative prices could be approximated by a loworder, autoregressive process, corresponding to the findings reported in Frenkel (198la). Similarly, one can show that a higher substitutability among domestic goods ( $\beta$ ), a lower share of labor ( $\gamma)^{17}$, a lower interest rate and 

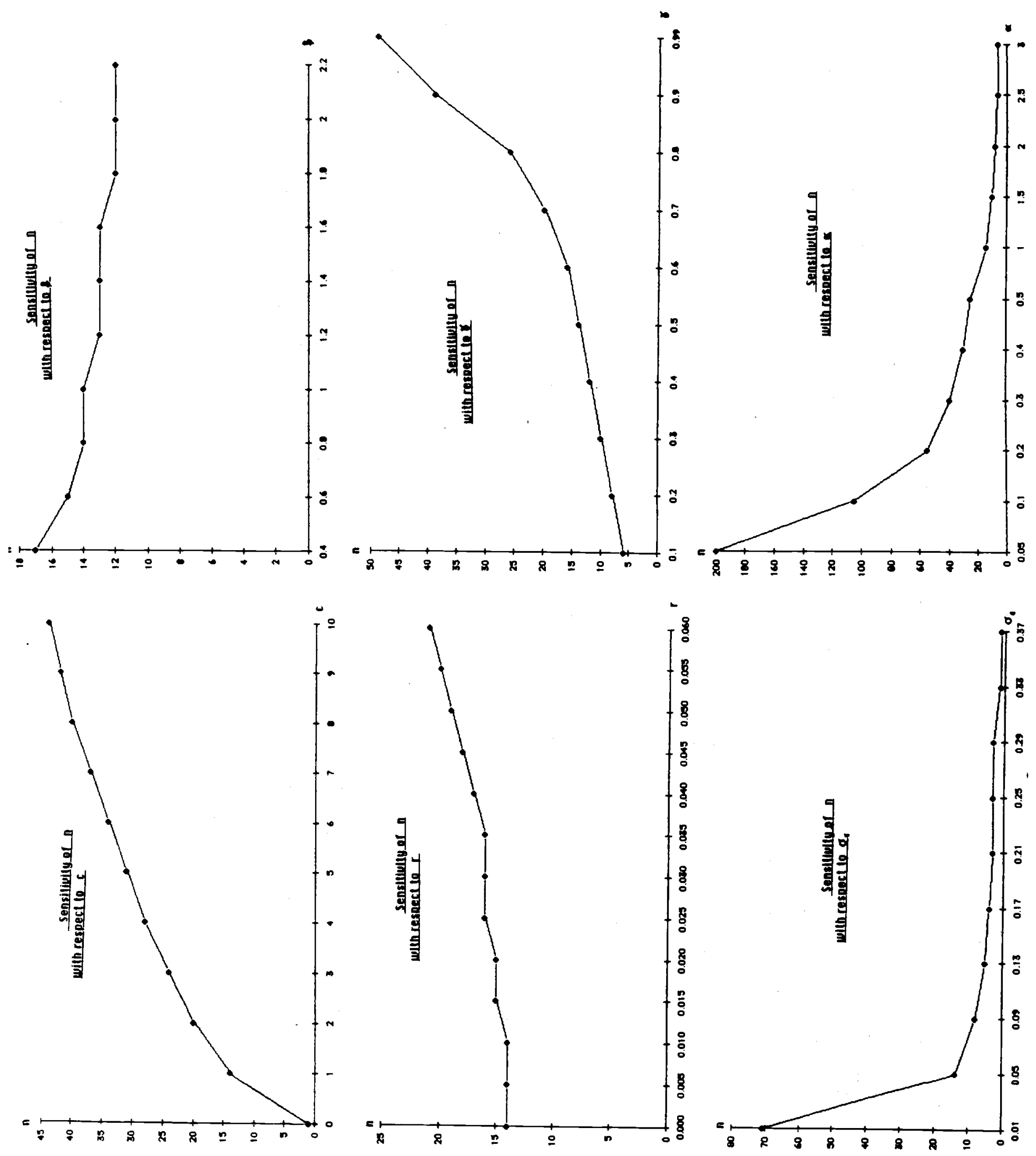
a lower cost of price adjustment reduce the optimal pre-setting horizon. Figure 3 summarizes simulation results, describing the dependence of optimal $n$ on the economic structure. ${ }^{18}$

The elasticity of average prices with respect to the exchange rate plays a key role in the covariation of the exchange rate and relative prices. In the presence of a longer pricing cycle, we find a tighter covariation. If $\frac{a}{n}$ approaches zero, as would be the case for smaller degree of substitutability or smaller exchange rate volatility, most of the short-run variations in relative prices can be explained by variations in the exchange rate.

As $\frac{a}{n}$ gets smaller, the observer will tend to reject the PPP hypothesis. Even for "intermediate" values of $\frac{a}{n}$, in an economy continuously subject to variations in the exchange rate, PPP would be frequently (almost always) violated. But as our pricing rule (14) demonstrates, this observation is fully consistent with a long-run view of PPP.

\section{Output, Deviations From PPP and Monetary Shocks}

The purpose of this section is to assess the importance of degree of goods substitutability in determining the output consequence of monetary shocks. The resultant output shock is proportional to the induced deviation from PPP. The discussion will identify two channels that link the degree of goods substitutability to the output effect of a monetary shock. A lower degree of goods substitutability will reduce, firstly, the responsiveness of output to a monetary shock and secondly, will result in a longer goods prices pre-setting horizon $(n)$, and consequently in a higher degree of persistency of output shocks. This raises the effective duration of the output shock induced by a given monetary shock.

The analysis in the previous sections considered the exchange rate path as being exogenously given, focusing on the resultant deviations from PPP. 
Because the focus of this section is the link between monetary shocks and deviation from PPP, it takes the path of monetary shocks as exogenously given, solving for the resultant exchange rate and output path. Let us define domestic output as the sum of the output of all produces $Y_{t}=\sum_{k=1}^{\ell} Y_{t, k}$, and let $Y^{\circ}$ denote the non-stochastic output level (i.e., the output level if all the stochastic shocks are zero). From equation 1 we obtain that:

$$
\log Y_{t}-\log Y^{0}=\alpha\left(e_{t}-\bar{p}_{t}+\frac{\theta_{o}}{a}\right)
$$

Thus, aggregate output deviates from its deterministic level in proportion to the stochastic deviation from PPP, the factor of proportionality being the degree of domestic/foreign goods substitutability. To further understand the link between money and output, let us complete the money-market specification. To simplify, let us take the simplest form of the demand for money:

$$
m_{t}^{d}=y_{t}+\bar{p}_{t}
$$

where output is given by

$$
y_{t}=\alpha\left(e_{t}-\bar{p}_{t}\right)
$$

The supply of money is assumed to follow a random walk:

(26)

$$
m_{t}=m_{t-1}+n_{t}
$$


Money-market equilibrium $\left(m_{t}^{d}=m_{t}\right)$ allows us, for a given pre-setting horizon $(n)$, to derive the path of prices and the exchange rate. To simplify notation, let us solve for the case where the prices are pre-set for two periods $(n=2)$. Applying equation 17 we find that in such a case

$$
\bar{p}_{t}=\frac{\theta_{0}}{a}+E_{t-1} e_{t}+\frac{a}{2}\left(e_{t}-E_{t-1} e_{t}\right)
$$

Combining equations $23-27$ allows us to solve for the rational expactation path of the exchange rate, obtaining that:

$$
e_{t}-E_{t-1} e_{t}=\frac{n_{t}}{\alpha\left(1-\frac{a}{2}\right)+\frac{a}{2}}
$$

By applying the definition of a to equation 28 we find that a higher degree of goods substitutability reduces the exchange rate shock induced by a monetary innovation. Applying equations 27-28 we obtain that the stochastic deviation from PPP and output are given by:

$$
e_{t}-\bar{p}_{t}+\frac{\theta_{0}}{a}=n_{t} \frac{1-\frac{a}{2}}{a\left(1-\frac{a}{2}\right)+\frac{a}{2}}
$$

$$
\log Y_{t}-\log Y_{0}=\eta_{t} \frac{a\left(1-\frac{a}{2}\right)}{\alpha\left(1-\frac{a}{2}\right)+\frac{a}{2}}
$$

Inspection of equations 29-30 reveals that a smaller degree of goods substitutability $(d \alpha<0, d a<0)$ raises the exchange rate and relative price effect but reduces the output effect of a given monetary shock. Thus, there is a trade-off between a price and a quantity adjustment. It is noteworthy that for small substitutability between domestic and foreign goods $(\alpha<1)$ we observe an overshooting of the exchange rate (i.e. de $\left.t / d \eta_{t}>1\right) .19$ 
Equations (28)-(30) can be used to infer the conditional variances, denoted by $\quad v_{t-1}$ (i.e., $\left.v_{t-1}\left(X_{t}\right)=E_{t-1}\left[\left(X_{t}-E_{t-1}\left(X_{t}\right)\right)^{2}\right]\right)$ :

$$
\begin{gathered}
{\left[\alpha\left(1-\frac{a}{2}\right)\right]^{2} v_{t-1}\left(e_{t}\right)=v_{t-1}\left(y_{t}\right)} \\
\left(1-\frac{a}{2}\right)^{2} v_{t-1}\left(e_{t}\right)=v_{t-1}\left(e_{t}-\bar{p}_{t}+\frac{\theta_{o}}{a}\right) .
\end{gathered}
$$

Note that the volatility of the exchange rate exceeds relative price volatility by $\left(1-\frac{a}{2}\right)^{2}$. Figure 4 plots the dependency of the three conditional variances on the degree of substitutability of domestic and foreign goods. A smaller substitutability is associated with greater volatility of prices and smaller volatility of output. Our analysis can be extended for a general length of the pricing cycle $(n)$. Following the steps described in the derivations of $(28)-(30)$ we find that:

$$
e_{t}-E_{t-(n-1)} e_{t}=\sum_{k=0}^{n-2} \frac{1}{\alpha+(1-\alpha) \frac{a}{n} \frac{k+1}{1-k b}} n_{t-k}
$$

$$
e_{t}-\bar{p}_{t}+\frac{\theta_{0}}{a}=\sum_{k=0}^{n-2} \frac{1-\frac{a}{n} \frac{k+1}{1-k b}}{a+(1-\alpha) \frac{a}{n} \frac{k+1}{1-k b}} n_{t-k}
$$

$$
\log Y_{t}-\log Y_{0}=\sum_{k=0}^{n-2} \frac{a\left[1-\frac{a}{n} \frac{k+1}{1-k b}\right]}{\frac{a}{n+(1-\alpha)} \frac{k+1}{1-k b}} n_{t-k}
$$




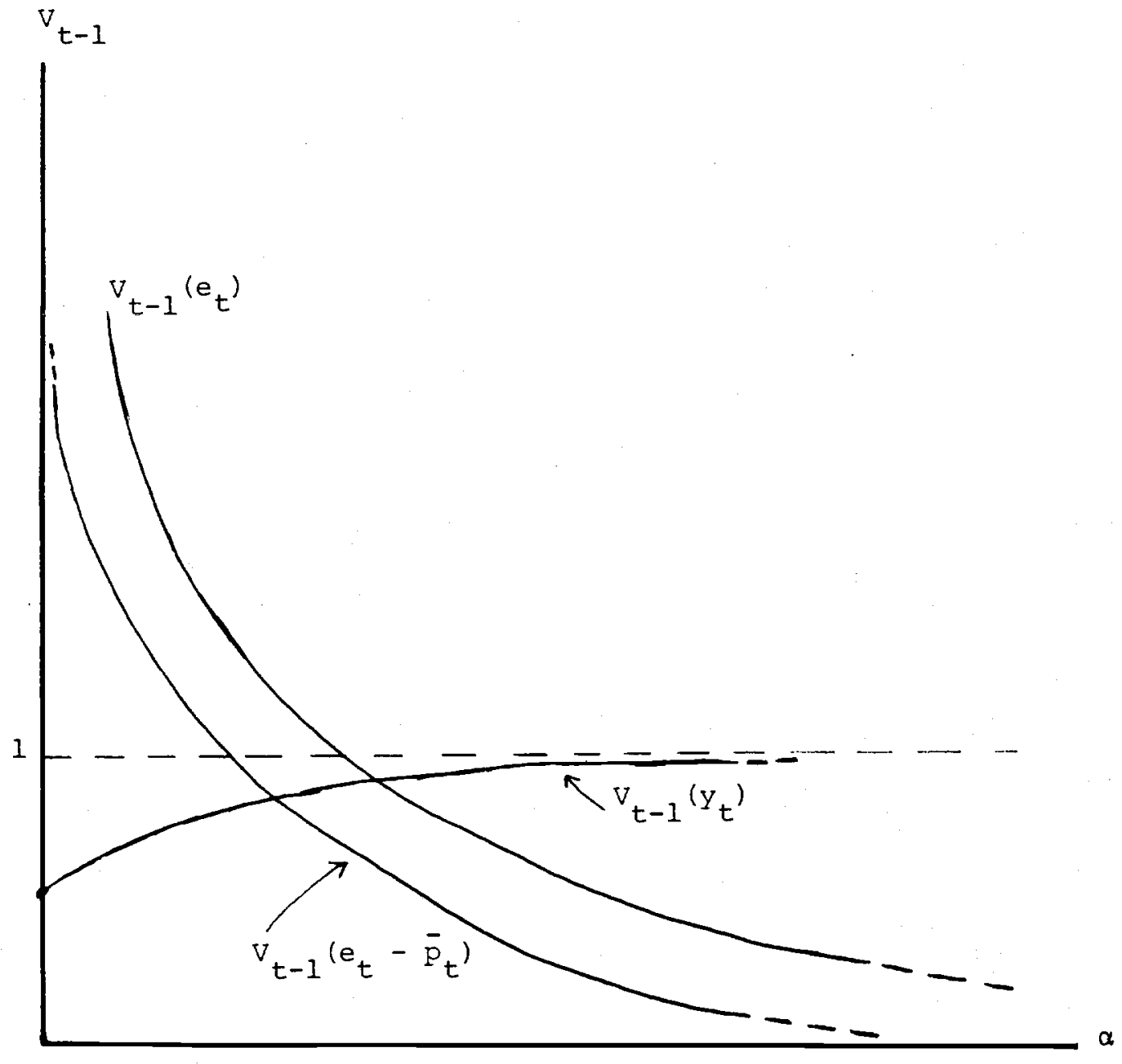

Figure 4 
Inspecting (33) $-(35)$ reveals that a given monetary shock $\left(n_{t}=1\right)$

will generate relative price and output dynamics similar to those described in Figure 2. The impact effect of the shock is reflected in a depreciation of both the real and the nominal exchange rates and a positive output shock. During the admustment we observe gradual adjustment of relative prices, which will mitigate the initial output shock. The exchange rate path is determined by $a$. If $a<1$ we observe an overshooting, and the exchange rate will appreciate during the adjustment. As in Section 3 , we observe an adjustment which accelerates over time till the adjustment is accomplished (after n-1 periods). 20 The cycle length is determined by the degree of staggering $(n)$, in a manner described in Appendix A. As is shown there, lower goods substitutability raises optimal $n$. This would prolong the output effect of a given monetary shock. Thus, the degree of goods substitutability has two opposing effects on the responsiveness of output to monetary shocks. A higher degree of goods substitutability raises the magnitude but reduces the duration of the output shock induced by a monetary innovation. At the limiting case of perfect goods substitutabiltiy $(a \rightarrow 1, \alpha \rightarrow \infty)$ we are in the flexible equilibrium case $(n=1)$, where monetary shocks do not affect output.

\section{Output, Deviations From PPP and Real Shocks}

The purpose of this section is to evaluate the path of adjustment to real shocks. Suppose, for example, that productivity varies over time. Thus, $q$ in equation 2 is subject to stochastic shocks, implying that the long-run equilibrium relative prices $\left(\frac{{ }_{0}}{a}\right.$, see equation 6 and footnote 13$)$ change over time. Let us denote by $\theta_{t}$ the $\theta$ at the time $t$ that corresponds to $q_{t}$. Suppose that the evolution of productivity is summarized by a random walk path of $\theta$ : 


$$
\frac{\theta_{t+1}}{a}=\frac{{ }^{\theta} t}{a}+\tau_{t}
$$

Following the steps described in the derivations of $(28)-(30)$ we find that:

$$
e_{t}-E_{t-(n-1)} e_{t}=\sum_{k=0}^{n-2} \frac{(\alpha-1) \frac{a}{n} \frac{k+1}{1-k b}}{\alpha+(1-\alpha) \frac{a}{n} \frac{k+1}{1-k b}} \tau_{t-k}
$$$$
\bar{p}_{t}-E_{t-(n-1)}\left(\bar{p}_{t}\right)=\sum_{k=0}^{n-2} \frac{a \frac{a}{n} \frac{k+1}{1-k b}}{\alpha+(1-\alpha) \frac{a}{n} \frac{k+1}{1-k b}} \tau_{t-k}
$$

$$
\begin{gathered}
e_{t}-\bar{p}_{t}-E_{t-(n-1)}\left(e_{t}-\bar{p}_{t}\right)=-\sum_{k=0}^{n-2} \frac{\frac{a}{n} \frac{k+1}{1-k b}}{\alpha+(1-\alpha) \frac{a}{n} \frac{k+1}{1-k b}} \tau_{t-k} \\
y_{t}-E_{t-(n-1)} y_{t}=-\sum_{k=0}^{n-2} \frac{\alpha \frac{a}{n} \frac{k+1}{1-k b}}{\alpha+(1-\alpha) \frac{a}{n} \frac{k+1}{1-k b}}{ }^{\tau} t-k
\end{gathered}
$$

Suppose, for example, an adverse supply shock occurs at time $t$. It leads to a rise at time $t$ in the prices of those producers that start a new pricing cycle at time $t$ and a corresponding drop in output. The price level rises by $\Delta \overline{\mathrm{p}}_{t}=\frac{\alpha \mathrm{a}}{\mathrm{n} \alpha+(1-\alpha) \mathrm{a}}$ and output drops $\left(\Delta \mathrm{y}_{t}=-\Delta \overline{\mathrm{p}}_{t}\right)$. If the substitutability between domestic and foreign goods is small $(\alpha<1)$, we need exchange rate appreciation to regain equilibrium. $\left(\Delta e_{t}=(\alpha-1) \Delta \vec{p}_{t}\right)$. If the substitutability is significant enough $(\alpha \geq 1)$, the drop in output is large enough to induce a depreciation which will mitigate the induced output drop. Independently of the direction of the exchange rate adjustment, we will observe a rise in the relative price of domestic goods $\left(\Delta\left(\bar{p}_{t}-e_{t}\right)=\frac{\Delta \bar{p}_{t}}{\alpha}\right)$. At time $t+1$ we observe a further adjustment of prices, exçhange rate, and output. The direction of adjustment is the same as in $t$. The effect of a 


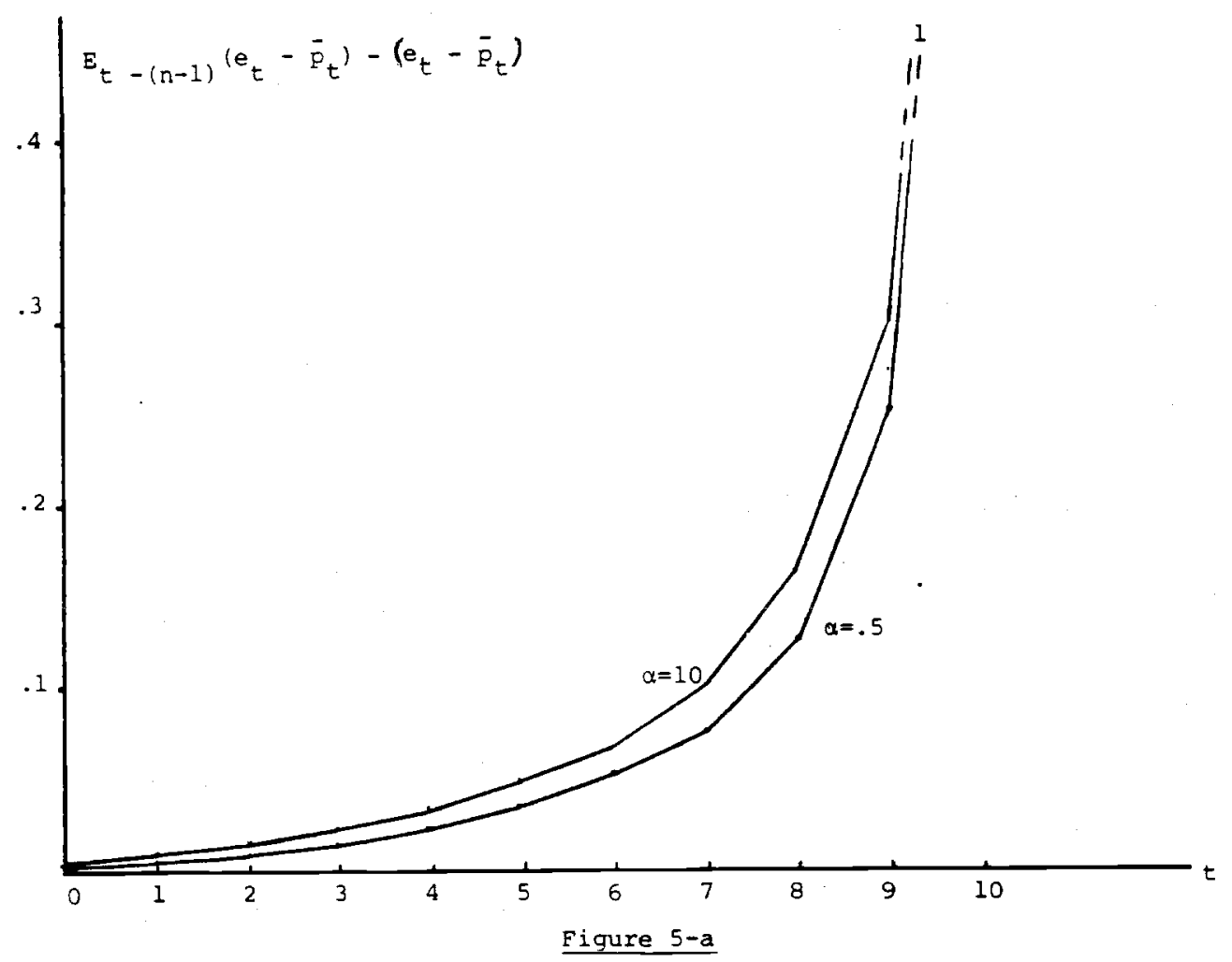

(drawn for $B=1, \gamma=1 / 2, \ell=22, n=11, \tau_{0}=1$ )

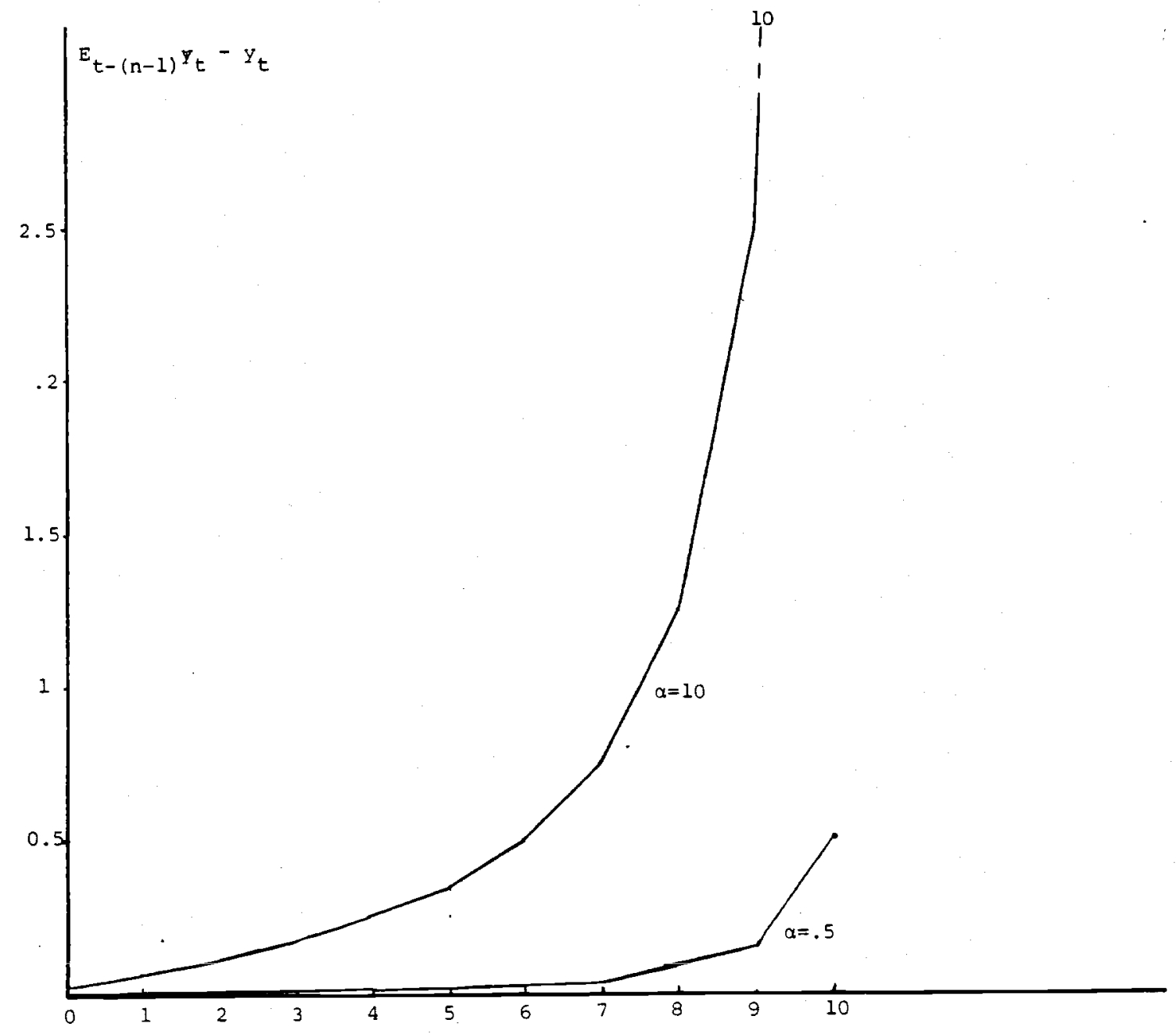

Figure $5-b$ 
staggered price path is that the adjustment at $t+1$ exceeds the adjustment at $t$, and we observe an accelerating adjustment to the new long-run equilibrium. In the long run (i.e., after $n-1$ periods) the effect of $\tau_{t}$ is that prices rise by $\alpha \tau_{t}$, output drops by $-\alpha \tau_{t}$ and the exchange rate depreciates by $(a-1) \tau$. Figures $5 a-b$ describe the adjustment path of relative prices and output to an adverse-productivity shock.

\section{Concluding Remarks}

The present paper has demonstrated that observable deviations from PPP can be explained by the presence of optimally staggered prices in a monopolistic competitive economy. In such an economy, PPP holds as a long -run proposition.

Among the limitations of the paper is the lack of a dynamic analysis of the path that brought the economy into a symmetric staggered pricing equilibrium. Suppose, for example, that we observe in the present period an unexpected change in the stochastic structure. We can expect such a change to trigger a resetting of the price path by some producers. The tendency to reset the price path should be stronger for those producers that had pre-set prices most recently. Such an attempt would tend to destroy the initial nonsynchronized equilibrium. An interesting task would be to derive the equilibrium path that corresponds to such an adjustment.

One of the key assumptions used in this paper concerns the timing of pricing decisions: It was assumed that the various producers are distributed uniformely over time, so that at each point in time a fraction $\left(\frac{1}{n}\right)$ of the producers determine the time path of prices. With this assumption the complexity of the problem was reduced significantly. In practice, however, it is evident that in many industries the pricing decisions are made at specific periods of time that are determined frequently by industry specific 
considerations (like the season of the year, the end and the beginning of the school year, and the like). Furthermore, it was assumed that each producer sets price for precisely $n$ periods. Again, in reality one typically observes that the length of the pricing cycle differs across sectors in the economy. Such considerations were not allowed in the present analysis, and their incorporation would constitute a useful extension. Finally, since the present paper modeled explicitly the behavior of various producers in a single industry the analysis deals really with deviations from the law of one price rather from the broader concept of purchasing power parity. 


\section{Appendix A}

The purpose of this Appendix is to study the optimal price-setting rule. This is done in two stages. First, assuming a given pre-setting horizon (given $\mathrm{n}$ ) we find the optimal pre-setting rule. Next, we evaluate the determinats of optimal $n .21$

a. The optimal pre-setting rule $\left(p_{t+k}^{k}\right)$

We found in the text that in a flexible equilibrium the optimal price is $\tilde{p}_{k}$, given by (4). This solution was arrived at by solving the following problem:

(A1)

$$
\operatorname{Max}_{\mathrm{k}} \quad \Gamma\left(\mathrm{p}_{\mathrm{k}}\right)
$$

where

$$
\Gamma\left(p_{k}\right)=P_{k} D_{k}\left(P_{k}\right)-\bar{P} \cdot L_{k} \cdot
$$

If producer $k$ charges $\mathrm{P}_{\mathrm{k}}$ instead of $\tilde{\mathrm{P}}_{\mathrm{k}}$, his profits can be approximated by

$$
\Gamma\left(p_{k}\right)=\Gamma_{0}\left(\tilde{p}_{k}\right)-\Gamma_{2}\left(\tilde{p}_{k}-p_{k}\right)^{2}
$$

(A2) corresponds to the second-order Taylor expansion of profits around $\tilde{p}_{k} \cdot \Gamma_{o}\left(\tilde{p}_{k}\right)$ are profits at the optimum, and $\Gamma_{2}=-\frac{1}{2} \cdot \frac{\partial^{2} \Gamma}{\partial\left(p_{k}\right)^{2}}$, evaluated at $\tilde{p}_{k}$. Suppose now that producer $k$ wishes to pre-set $p_{t+k}$ in period $t\left(p_{t+k}^{k}\right)$. Assuming risk neutrality, $p_{t+k}^{k}$ is the solution of 
(A3)

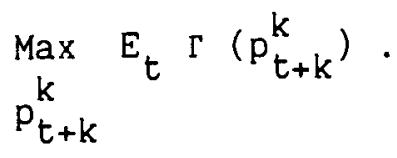

Or, applying (A2)

$\left(A 3^{\prime}\right)$

Note that

$$
\operatorname{Max}_{p_{t+k}^{k}} E_{t}\left[\Gamma_{o}\left(\tilde{p}_{t+k}\right)-\Gamma_{2}\left(\tilde{p}_{t+k}-p_{t+k}^{k}\right)^{2}\right] .
$$

$$
E_{t}\left[\left(\tilde{p}_{t+k}-p_{t+k}^{k}\right)^{2}\right]=\left(E_{t} \tilde{p}_{t+k}-p_{t+k}^{k}\right)^{2}+v_{t}\left(\tilde{p}_{t+k}\right)
$$

where $v_{t}\left(x_{t+k}\right)$ is the variance of $x_{t+k}$, conditional on information available at period $t$. Because the path of $\tilde{p}_{t+k}$ is independent from $p_{t+k}^{k}$, profits will be maximized by:

$$
p_{t+k}^{k}=E_{t} \tilde{p}_{t+k}
$$

b. The optimal pre-setting horizon (n)

We derive optimal $\mathrm{n}$ in several steps. First, we derive the expected loss from pre-setting $p_{t+k}^{k}$ in period $t$. Next; for a given $n$ we measure the cost of pre-setting prices per cycle as the net present value of expected losses during the cycle. Finally, we specify the costs of pricing decisions to obtain the n.p.v. of profits in our economy. Optimal $n$ is the result of minimizing this last expression.

Applying (A3)-(A5) we obtain that expected profits in period $t+k$ resulting from charging $p_{t+k}^{k}$, are:

$$
E_{t} \Gamma\left(p_{t+k}^{k}\right)=E_{t} \Gamma_{0}\left(\tilde{p}_{t+k}\right)-\Gamma_{2} E_{t}\left(\tilde{p}_{t+k}-E_{t} \tilde{p}_{t+k}\right)^{2} .
$$

Therefore, the expected loss from pre-setting the price for period $t+k$ is : 
(A7) $-\Gamma_{2} E_{t}\left(\tilde{p}_{t+k}-E_{t} \tilde{p}_{t+k}\right)^{2}$.

This result is measured in terms of nominal profits in period $t+k$. We obtain a real measure by deflating $\Gamma_{2}$ by $\overline{\mathrm{P}}_{t+k}$, the price level. For large numbers of producers, assuming that we are close to the flexible equilibrium, we can approximate

$$
\Gamma_{2}^{\prime}=\frac{\Gamma_{2}}{\bar{P}} \approx-\frac{1}{2}(\delta-1) \delta\left(1-\frac{1}{\gamma}\right)\left[\frac{\delta}{\gamma(\delta-1)}\right]^{\frac{1}{\gamma}-1}
$$

We denote by $\mathrm{H}_{t+k}$ the loss in real terms:

$$
H_{t+h} \simeq \Gamma_{2}^{\prime} E_{t}\left(\tilde{p}_{t+h}-E_{t} \tilde{p}_{t+h}\right)^{2}
$$

Notice that $\tilde{p}_{t+h}=p_{t+h}^{o}$, and $E_{t} \tilde{p}_{t+h}=p_{t+h}^{h}$. Using these facts, we can apply (14) to obtain a measure of $H_{t+j}$ in a rational expectation equilibrium:

$$
H_{t+h}=\Gamma_{2}^{\prime} \cdot E_{t}\left(\sum_{k=0}^{h-1} \frac{a}{1-k b} \varepsilon_{t+h-k}\right)^{2}, h \geq 1 .
$$

Or, alternatively:

$$
H_{t+h}=\Gamma_{2}^{\prime} a^{2} \sigma_{\varepsilon}^{2}\left(\sum_{k=0}^{h-1} \frac{1}{(1-k b)^{2}}\right), h \geq 1 .
$$

If a typical producer pre-sets the price path for $n$ periods, the expected net present value of the loss from pre-setting (in terms of the beginning of the cycle) is:

$$
\begin{gathered}
\Omega(n)=\sum_{n=1}^{n-1} H_{t+h} /(1+r)^{h} \text { for } n \geq 2 \\
\Omega(1)=0 \text { for } n=1 .
\end{gathered}
$$


where $r$ denotes the real interest rate, assumed to be exogenously given. Applying (All) we find that

$$
\Omega(n)=\Gamma_{2}^{\prime} a^{2} \sigma_{\varepsilon}^{2}\left[\sum_{h=1}^{n-1} \sum_{k=0}^{h-1}\left(\frac{1}{(1-k b)^{2}(1+r)^{h}}\right)\right], n \geq 2 ;
$$

and

$$
\Omega(1)=0 \text {. }
$$

To derive a measure of expected profits, we should include in our consideration the role of the cost of pricing decisions. Suppose that each pricing decision involves cost $c$. To simplify derivation, suppose that in period zero we start a new pricing cycle. The net present value of profits, resulting from following a policy of pre-setting the price path every $n$ periods, is :

$$
D_{n}=\tilde{D}-\sum_{h=0}^{\infty}[\Omega(n)+c] \frac{1}{(1+r)^{h n}}
$$

where $\tilde{D}$ is the net present value in a flexible-price equilibrium (i.e., where $P_{t}=P_{t}^{0}=\tilde{P}_{t}$ for all $t$, and $c=0$ ). We use $\tilde{D}$ as a benchmark. To obtain net profits, we adjust $\tilde{D}$ by the n.p.v. of costs resulting from presetting the price path (n.p.v. of $\Omega(n)$ ) and the n.p.v. of the cost of pricing decisions (n.p.v. of $c$ ). A strategy of $n=1$ will minimize the n.p.v. of $\Omega$ (to zero), at a cost of maximizing the n.p.v. of c. Alternatively, setting the price path for the entire future $(n \rightarrow \infty)$ would maximize the n.p.v. of $\Omega(n)$, minimizing the n.p.v. of c. In general, we will balance the two costs at the margin, and $n$ is found by maximizing $D_{n}$. Following some tedious calculations we find that

$$
\frac{\Delta \mathrm{n}}{\Delta\left(\mathrm{a} \sigma_{\epsilon}\right)}<0, \frac{\Delta \mathrm{n}}{\Delta \mathrm{c}}>0
$$

A rise in ${ }^{a \sigma}{ }_{\varepsilon}$ implies that for a given pre-setting horizon, the costs 
of pre-setting have increased $\left(\frac{d \Omega}{d\left(a \sigma_{\varepsilon}\right)}>0\right) ;$ motivating a cut in the presetting horizon. If we take the limit of perfect substitutability between domestic and foreign goods $(\alpha \rightarrow \infty)$, we find that $\Omega(n) \rightarrow \infty$ for $n>1$ (because $\left.\Gamma_{2}^{\prime} \rightarrow \infty\right)$. Therefore, in this limiting case optimality calls for $n=1$, which is the case where $P_{t}=\tilde{P}_{t}$, and PPP holds at all times.22 Thus, a necessary condition for generating deviations from PPP is a limited degree of substitutability between domestic and foreign goods. 
Appendix B

The analysis in the text focused on the pricing behavior of domestic goods and assumed that foreign goods could enter the market priced at their PPP level. The purpose of this Appendix is to analyze deviations from PPP in an economy in which domestic prices of both foreign and domestic goods are treated symmetrically: each seller pre-sets the price path for several periods, resulting in a staggered price equilibrium for both domestic and foreign goods. The discussion is intended to demonstrate that, apart from the added complexity, the resultant deviations from PPP are similar to those analyzed in the text.

Consider an economy composed of a large number of producers and dealers selling foreign goods. Each of them is small enough to take the average prices of domestic and foreign goods as given. Let us denote by $\bar{P}$ and $\bar{P}_{f}$ the corresponding domestic average price of domestic and foreign goods.

The demand facing a domestic producer $(k)$ is given by:

$$
\left.\left.\left(\frac{\overline{\mathrm{P}}}{\mathrm{P}_{\mathrm{k}}}\right)^{\overline{\mathrm{B}}^{\prime}} \overline{\mathrm{P}}_{\mathrm{f}}\right)^{\mathrm{P}_{\mathrm{k}}}\right)^{\prime}
$$

Where $\bar{B}^{\prime}$ corresponds to the elasticity of demand with respect to the price set by domestic competitors, whereas $\bar{a}$ ' corresponds to the elasticity of demand with respect to the price set by foreign competitors. Note that $\bar{a}^{\prime}$ represents the elasticity of substitution between domestic and foreign goods. Production technology is the same in this case as in the text: 
where $L_{k}$ denotes labor input employed by producer $\mathbf{k}$. For simplicity of exposition we assume that labor is paid according to a domestic product deflator ( $\bar{P})$.

Analogously, domestic dealer selling foreign goods priced at $\mathrm{P}_{\mathrm{f}}$ faces a demand given by

$$
\left(\frac{\bar{P}_{f}}{P_{f}}\right)^{\bar{B}^{\prime}}\left(\frac{\bar{P}}{P_{f}}\right)^{\bar{\alpha}^{\prime}}
$$

Invoking the small country assumption, we assume that each dealer can import foreign goods at a given international price, taken to be one $\left(P^{*}=1\right)$. We solve this model as we did the model in the text. First, we derive the flexibile price equilibrium. Then we study the equilibrium for the case where domestic and foreign producers pre-set the price path for $\mathrm{n}$ and $\mathrm{m}$ periods, respectively.

Profit maximization in a flexible equilibrium implies that dealers of foreign goods would charge:

$$
\tilde{p}_{j}=e+h
$$

$$
\text { Where } h=-\log \left(1-\frac{1}{\bar{\beta}^{\prime}+\bar{\alpha}^{\prime}}\right) \equiv \frac{1}{\bar{\beta}^{\prime}+\bar{\alpha}^{\prime}} \text {, }
$$

and lower-case letters denote the logarithmic value of the corresponding upper-case variables. Domestic producer $k$, operating in a flexible equilibrium, will charge 
(B5)

$$
\begin{gathered}
p_{k}=\bar{\theta}_{0}^{\prime}+\bar{b}^{\prime} \bar{p}+\bar{a}^{\prime} \bar{p}_{f} \text { where: } \\
\bar{\theta}^{\prime}=\frac{h+\log \bar{\gamma}}{1+(\bar{\gamma}-1)\left(\bar{\alpha}^{\prime}+\bar{B}^{\prime}\right)}, \quad \bar{b}^{\prime}=\frac{1+(\bar{\gamma}-1) \bar{B}^{\prime}}{1+(\bar{y}-1)\left(\bar{\alpha}^{\prime}+\bar{B}^{\prime}\right)}
\end{gathered}
$$

and $\bar{a}^{\prime}=\frac{(\bar{\gamma}-1) \bar{\alpha}^{\prime}}{1+(\bar{\gamma}-1)\left(\bar{\alpha}^{\prime}+\bar{\beta}^{\prime}\right)} ;$ where $\bar{\gamma}=1 / y$.

Notice that $\bar{a}^{\prime}$ and $\bar{b}^{\prime}$ are related by an additive property: $\bar{a}^{\prime}+\bar{b}^{\prime}=1$.

If all producers operate in a flexible price environment, we find that the price of the domestic good $(p)$ deviates from the PPP level of foreign goods (e) by:

$$
p-e=h\left[1+\frac{1}{(\bar{\gamma}-1) \bar{\alpha}^{\prime}}\right]+\frac{\log \gamma}{(\bar{\gamma}-1) \bar{\alpha}^{\prime}}
$$

and the price of the domestic good deviates from the domestic price of foreign goods by:

$$
p-p_{f}=\frac{1}{\bar{\alpha}^{\prime}} \frac{1}{(\bar{\gamma}-1)}[h+\log \bar{\gamma}] .
$$

Both measures of deviations from PPP approach zero as $\bar{\alpha}^{\prime}$ approaches infinity, as would be the case if domestic and foreign goods were perfect substitutes. 
Suppose now that, due to the presence of gains from pre-setting the price path for several periods, domestic and foreign producers make pricing decisions every $n$ and $m$ periods, respectively. Thus, they pre-set the price path for $\mathrm{n}$ (and $\mathrm{m}$ ) periods. Assuming that producers and dealers are risk neutral, Appendix A demonstrated that a producer (or a dealer) that pre-set the price for period $t$ i periods ago will charge:

(B8)

$$
p_{t}^{i}=E_{t-i} \tilde{p}_{t}
$$

Thus, the resultant price for foreign goods is:

(B9)

$$
p_{f, t}^{i}=E_{t-i} e_{t}+h
$$

Applying equations (B5) and (B8) we find that a domestic producer that pre-set prices at period $t$ in a staggered, unsynchronized equilibrium will set its price at:

$$
p_{t}^{0}=\theta_{0}^{\prime}+b^{\prime} \sum_{j=1}^{n-1} p_{t}^{j}+a^{\prime} \sum_{i=0}^{m-1} E_{t-i} e_{t}
$$

$$
\text { where } \theta_{0}^{\prime}=\frac{\bar{\theta}_{0}^{\prime}+\bar{a}^{\prime} h}{1-\overline{\underline{b}}^{\prime}}, b^{\prime}=\frac{\bar{b}^{\prime}}{n-\bar{b}^{\prime}} \text { and } a^{\prime}=\frac{\bar{a}^{\prime}}{m\left(1-\frac{\bar{b}^{\prime}}{n}\right)} \text {. Note that } a^{\prime}
$$

and $b^{\prime}$ are related by another additive property:

$$
(n-1) b^{\prime}+m a^{\prime}=1
$$

We assume that the only source of uncertainty is the foreign exchange rate, which follows the random walk process (equation 10). 
For a given $\mathrm{n}$ and $\mathrm{m}$ we can solve for the pricing behavior. The duration of the pricing cycle ( $\mathrm{n}$ and $\mathrm{m}$ ) is determined endogenously in a manner described in Appendix A. The resultant deviations from PPP will have statistical properties similar to those described in the text. For example, if $m=n$, by solving equation $B 10$ recursively (applying equation 11) we find that (for $k \geq n$ ):

$$
p_{t}^{j}=\frac{\theta_{0}^{\prime}}{a^{\prime} n}+E_{t-(n-1)} e_{t}+\sum_{k=j}^{n-2} \frac{a^{\prime}(1+k)}{1-k b^{\prime}} \varepsilon_{t-k}
$$

Using the fact that $\bar{p}_{t}=\sum_{k=0}^{n-1} p_{t}^{n-k} / n$ we obtain:

$$
\bar{p}_{t}=\frac{\theta_{0}^{\prime}}{a^{\prime} n}+E_{t-(n-1)} e_{t}+\sum_{k=0}^{n-2} \frac{a^{\prime}(1+k)^{2}}{n\left(1-k b^{\prime}\right)} \varepsilon_{t-k}
$$

The resultant deviations of domestic prices from the PPP price of foreign $\operatorname{goods}\left(p^{*}+e-\bar{p}\right)$ is equal to:

$$
e_{t}-\vec{p}_{t}=-\frac{\theta_{0}^{\prime}}{a^{\prime} n}+\sum_{j=0}^{n-2}\left[1-\frac{a^{\prime}(1+j)^{2}}{n\left(1-j b^{\prime}\right)}\right] \varepsilon_{t-j} .
$$

A comparison between equation $\mathrm{B} 14$ and equation 18 from the text reveals that allowing for a symmetric treatment of the pricing of both domestic and foreign goods does not affect the nature of the resultant deviations from PPP. These follow a path similar to the one described in figures $2-3$.

The case of equal degrees of price staggering $(n=m)$ is useful as a benchmark for the assessment of the relative duration of the pricing cycle of each class of goods. As is shown in Appendix A, a rise in volatility reduces the length of a pricing cycle. As equation A9 shows, the appropriate volatility measure is the expected (squared) discrepancy between the pre-set price and the corresponding flexible price $\left[E_{t}\left(p_{t+h}^{h}-\tilde{p}_{t+h}\right)^{2}\right]$. In what 
follows we compare this volatility measure as it relates to home and foreign goods (sold domestically).23 This comparison is conducted for the case where $m=n$. With equal pre-setting horizon (h), this volatility measure is shown to be larger for traded goods, implying that the benchmark case where $m=n$ is suboptimal. Thus, the presumption is that the pricing cycle is longer for domestic goods.

Applying 84 and 9 we find that for foreign goods, sold domestically:

$$
E_{t}\left[p_{t+h}^{h}-\tilde{p}_{t+h}\right]^{2}=E_{t}\left[\sum_{j=1}^{h} \varepsilon_{t+j}\right]^{2}=h \sigma_{\varepsilon}^{2} .
$$

From $\mathrm{B} 8$ and 12 we get that

$$
\begin{gathered}
E_{t}\left[p_{f, t+h}^{h}-\tilde{p}_{f, t+h}\right]^{2}=E_{t}\left[\sum_{j=1}^{h} \frac{a^{\prime}(h+1-j)}{1-(h-j) b^{\prime}} \varepsilon_{t+j}\right]^{2}= \\
=\sum_{j=1}^{h}\left[\frac{a^{\prime}(h+1-j)}{1-(h-j) b^{\prime}}\right]^{2} \cdot \sigma_{\varepsilon}^{2} .
\end{gathered}
$$

Notice that an exchange rate innovation $\varepsilon_{t+j}$ affects $B 15$ by means of a unitary coefficient, whereas it affects $B 16$ at a lower rate (because $\left.\frac{a^{\prime}(h+1-j)}{1-(h-j) b^{\prime}}<1\right)$ Consequently, the volatility measure that is relevant for the assessment of the costs of pre-setting prices is higher for foreign goods (sold domestically). Thus, domestic production tends to mitigate the drop in profits that results from exchange rate volatility, implying a longer optimal duration of the pricing cycle of domestic goods relative to the pricing cycle of foreign goods sold domestically. 


\section{Footnotes}

1. This paper extends a previous study (entitled "Monopolistic Competition and Deviations from PPP", NBER W. P. \#1552), by studing the output and price effects of real and monetary shocks.

2. For a summary of empirical regularities, see Frenkel (1981b) and Mussa (1979).

3. For a test of the explanatory power of various exchange-rate approaches, see Meese and Rogoff (1983).

4. For studies on the nature of deviations from PPP see, for example, Isard (1977), Frenkel (1981a), Kravis, Heston and Lipsey (1982).

5. Empirical evidence (Frenkel (1981b)) has shown that deviations from PPP follow an $A R(1)$ process, with an autocorrelation of .9 , close enough to unity such that one cannot reject the random walk possibility.

6. For such a model, see Aizenman (1984) and Benninga and Protopapadakis (1984).

7. For a discussion on relative and absolute PPP, see Frenkel (1976). For a review of the PPP doctrine see, for example, Officer (1984) and Dornbusch (1985).

8. Monopolistic competitive equilibrium in an open economy was studied by Flood and Hodrick (1983). They focused on the role of inventory adjustment in explaining the business cycle. Dixit and Stiglitz revived the interest in monopolistic competition whereas Dornbusch (1976) revived the interest in pre-set pricing models of floating exchange rates. On monopolistic competition in the context of trade models see Helpman and Krugman (1985). 
9. To simplify, we neglect the role of fluctuations in present income in determining the demand. Thus, our analysis corresponds to the case where the demand is determined by the permanent income and the real interest rate, both of which are assumed to be constant. In general, we can further enrich the analysis by allowing the demand to be a function of both income and relative prices.

10. We consider the case where the we do not allow for pre-set prices contingent on future (presently unavilable) information. At the extreme case, where we would make optimal use of all future information in a contingent pricing system, we would converge on the flexible equilibrium economy, described earlier. This paper does not attempt to provide a theoretical justification for the existence of non-contingent prices. Rather, their existence is taken for granted, and the present work attempts to analyze the statistical properties of the resultant deviations from PPP. For studies on goods price rigidities, see Carlton $(1979,1985)$ and the references thereupon.

11. The present formulation is related to.Fischer (1977), who studies the determinations of contracts in the presence of two-period staggered contracts. The new aspect of the present discussion is in allowing for endogenous determination of the extent of staggering prices, focusing on the role of the degree of substitutability between various goods and the stochastic structure in explaining the nature of the resultant equilibrium. Our approach is closer to Fischer (1977) than to Taylor (1979), who considers a staggered equilibrium that sets one price for the pre-setting horizon, which is taken to be exogenously given. The issues addressed in this paper can be casted in terms of Taylor's framework, where each pricing decision set a price (and not a price path). This 
paper apply Fischer's formulation because it allows for a more tractable analysis regarding the role of goods substitutability in the determinations of the optimal frequency of pricing decisions and the implied path of the purchasing power ratio.

12. The random walk choice is motivated by the empirical regularities observed in the last decade.

13. Notice that $\frac{{ }_{0}}{a}=\frac{\bar{\theta}_{0}}{\bar{a}}$, equal to the relative price obtained in a flexible equilibrium ( $\tilde{p}-e, \operatorname{see}(6))$.

14. Note that as the substitutability between domestic and foreign goods rises $(\alpha \rightarrow \infty), \frac{\theta_{0}}{a}$ approaches zero, in accord with absolute PPP.

15. Note that

$E_{t-(n-1)}\left(p_{t}^{j}\right)=E_{t-(n-1)}\left[E_{t-j}\left(p_{t}^{0}\right)\right]=E_{t-(n-1)} p_{t}^{0}=p_{t}^{n-1}$ for $0 \leq j \leq n-1$

16. It is noteworthy that the convex adjustment of relative prices(i.e. $\frac{\Delta^{2}\left[e_{t}-\bar{p}_{t}\right]}{(\Delta j)^{2}}<0$ is a result of the staggered nature of the price path set by various producers. For example, in Dornbusch (1976) the speed of adjustment of relative prices diminishes over time (i.e. $\frac{\Delta^{2}\left[e_{t}-\bar{p}_{t}\right]}{(\Delta j)^{2}}>0$ ).

17. A rise in labor share $(\mathrm{d} \gamma>0)$ imply a higher share of the variable factor, enabeling a more flexible output adjustment to shocks to relative prices. This has the effect of reducing the costs associated with pre-set prices, prolonging the length of the pricing cycle.

18. The simulations are conducted for initial values of $\alpha=\beta=1, \quad \gamma=.5, \quad \ell=22$, $r=0, c=1$. I am indebted to Jae Sun $Y i$ for helpful assistance in the computation.

19. It can be shown that if the income elasticity of the demand for money is $\xi$ overshooting will take place if $\xi \alpha\left(1-\frac{a}{2}\right)+\frac{a}{2}<1$. Thus, a smaller income elasticity of the demand for money raises the needed exchange rate adjustment. 
$\Delta^{2}\left[\frac{1}{\alpha+(1-\alpha) \frac{a}{n} \frac{k+1}{1-k b}}\right] /(\Delta k)^{2}=\operatorname{sign}[\alpha(1+b)-a]$. Using definitions it follows that $\delta>1$ necessitates $\alpha(1+b)-a>0$.

21. The problem of an optimal pre-setting horizon is related to the question of optimal labor contract length, as addressed by Gray (1978). A new aspect of the present discussion is the focus on the role of market structure (degree of goods substitutability) and the presence of endogenous staggered prices.

22. Alternatively, as $\alpha \rightarrow 0$ we find that $a \rightarrow 0$. In such a case $\Omega \rightarrow 0$, and $\mathrm{n} \rightarrow \infty$. This result reflects our assumption that the only uncertainty sources are shocks to the exchange rate. In a more general analysis, which allows for the presence of productivity and domestic demand shocks, as $\alpha \rightarrow 0$ we would find that $n$ would approach its closed economy optimal value, whereas as $\alpha \rightarrow \infty \mathrm{n} \rightarrow 1$

23. Note that the appropriate volatility measure (equation A9) is the result of multiplying the price volatility measure by $\Gamma_{2}^{\prime}$, reflecting the second order term in the Taylor expansion of profits. In what follows we assume $\Gamma_{2}^{\prime}$ to be equal for both sectors, focusing on the relative price volatility. 


\section{References}

Aizenman, Joshua, "Modeling Deviations from PPP," International Economic Review, 25, $1984,175-191$.

Benninga, Simon and Aris Protopapadakis "The Equilibrium Pricing of Exchange Rates and Assets When Trade Take Time." Working Paper, University of PA, 1984.

Carlton, Dennis, W. "Contracts, Price Rigidities and Market Equilibrium," Journal of Political Economy, 87, 1979, 1034-1062.

, "The Rigidity of Prices" Working Paper, 1985.

Dixit, Avinash and Joseph Stiglitz, "Monopolistic Competition and Optimum Product Diversity "American Economic Review, June 1977.

Dornbusch, Rudiger,"Expectations and Exchange Rate Dynamics," Journal of Political Economy 84, 1976: 1161-76.

, "Exchange Rate and Prices" Working paper, presented in the NBER Summer Institute, 1985.

, "Purchasing Power Parity,"NBER WP no. 1591, 1985; New Palgrave Directory of Economics, Forthcoming.

Flood, Robert P. and Hodrick, Robert J., "Optimal Price and Inventory Adjustment In an Open Economy Model of the Business Cycle," NBER Working Paper Series, No. 1089, March 1983.

Fischer, Stanley, "Wage Indexation and Macroeconomic Stability," in Karl Brunner and Allan H. Meltzer, eds., Stabilization of Domestic and International Economy, Vol. 5, Carnegie-Rochester Conferences on Public Policy, a supplementary series to the Journal of Monetary Economics, Suppl. 1977, 107-47.

Frenkel, Jacob A., "A Monetary Approach to the Exchange Rate: Doctrinal Aspects and Empirical Evidence," Scandinavian Journal of Economics, 78 (May 1976), pp. 200224. Reprinted in Jacob A. Frenkel and Harry G. Johnson, eds., The Economics of Exchange Rates: Selected Studies, Reading, Mass., Addison-Wesley, 1978.

, "The Collapse of Purchasing Power Parities During the 1970 's,"European Economic Review, 16 (Eebruary 1981a), pp. 145-165.

, "Flexible Exchange Rates, Prices and the Role of 'News': Lessons from the 1970's," Journal of Political Economy, 89 (August 1981b), pp. 665-705.

Giovannini Alberto, "Exchange Rates and Traded Goods Prices", Working paper, Columbia University, 1985.

Gray, Jo Anna, "On Indexation and Contract Length," Journal of Political Economy, February $1978,86,1-18$.

Helpman Elhanan and Paul Krugman, Market Structure and Foreign Trade, MIT Press, 1985. 
Isard, Peter, "How Far Can We Push the Law of One Price "American Economic Review, December, 1977.

Katseli, Louka, T., "Real Exchange Rates in the 1970's," in J. F. O. Bilson and R. C. Marston, eds., Exchange Rate Theory and Practice, NBER Conference Report, University of Chicago Press, 1984.

Kravis, Irving B., Alan Heston, and Robert Summers, World Product and Income: International Comparisons of Real GDP, Baltimore, Johns Hopkins University Press, 1982 .

Meese, Richard and Kenneth Rogoff, "The Out-of-Sample Failure of Empirical Exchange Rate Models" printed in Exchange Rates and International Macroeconomics Jacob

A. Frenkel, (ed.) the University of Chicago Press, 1983.

Mussa, Michael, "The Exchange Rate, the Balance of Payments, and Monetary and Fiscal Policy under a Regime of Controlled Floating," Scandinavian Journal of Economics, 78 (May 1976), pp. 229-248. Reprinted in Jacob A. Frenkel and Harry G. Johnson, eds., The Economics of Exchange Rates, Reading, Mass., AddisonWesley, 1978.

, "Empirical Regularities in the Behavior of Exchange Rates and Theories of Foreign Exchange Market" In Policies for Employment, Prices and Exchange Rates, K. Brunner and A. H. Meltzer (eds.), Carnegie-Rochester Conference Series, Vol. 11, 1979.

, "Sticky Prices and Disequilibrium Adjustment in a Rational Model of the Inflationary Process." American Economic Review, 71. December 1981: 1020-27.

Officer, Larry, "Purchasing Power Parity and Exchange Rates," JAI Press, 1984.

Rotemberg, Julio, J. "Sticky Prices in the United States" Journal of Political Economy, Volume 90, No. 6, December 1982, 1187-1211.

Sheshinski, Eytan, and Weiss Yoram, "Inflation and Costs of Price Adjustment," Review of Economics Studies 44, June 77: 287-304.

Svensson, Lars E. O., "Sticky Goods Prices, Flexible Asset Prices, Monopolistic Competition, and Monetary Policy" Working Paper, Institute for International Economic Studies, University of Stockholm, February 1985.

Taylor, John B., "Aggregate dynamics and Staggered Contracts," Journal of Political Economy 8, February 1980: 1-17. 